\title{
Modelo de ciclo de vida de empreendimentos sociais
}

\author{
Alexandre Meira de Vasconcelos \\ Universidade Federal de Santa Catarina \\ Álvaro Guillermo Rojas Lezana \\ Universidade Federal de Santa Catarina
}

\begin{abstract}
Este artigo apresenta um modelo de ciclo de vida de empreendimentos sociais. Os dados primários foram obtidos em entrevistas com fundadores de 10 empreendimentos sociais de Curitiba (PR) acerca da história de vida da organização. A análise qualitativa dos dados identificou cinco etapas de evolução (Ação Social, Associação, Visibilidade Social, Rede Social e Representatividade Social) com, respectivamente, seis momentos de crise que determinam a passagem para uma etapa posterior (Desequilíbrio Social, Identidade, Foco, Controle, Responsabilização e Ética). O estudo reafirma as diferenças entre o empreendedorismo social e o privado e justifica o tratamento diferenciado entre eles. O modelo pode subsidiar a decisão dos gestores sobre o futuro da organização, bem como de financiadores públicos e privados, gestores de redes sociais, pesquisadores, consultores, administradores públicos, entre outros stakeholders, e abre caminho para outros estudos sobre o tema.
\end{abstract}

Palavras-chave: empreendedorismo social; ciclo de vida; terceiro setor.

Modelo de ciclo de vida de emprendimientos sociales

Este artículo presenta un modelo de ciclo de vida de emprendimientos sociales. Los datos primarios se obtuvieron en entrevistas con fundadores de 10 emprendimientos sociales de Curitiba (PR) acerca de la historia de vida de la organización. El análisis cualitativo de los datos identificó cinco etapas de evolución (Acción Social, Asociación, Visibilidad Social, Red Social y Representatividad Social) con, respectivamente, seis momentos de crisis que determinan el paso para una etapa posterior (Desequilibrio Social, Identidad, Enfoque, Control, Responsabilización y Ética). El estudio reafirma las diferencias entre el emprendimiento interno social y el privado y justifica el tratamiento diferenciado entre ellos. El modelo puede subsidiar la decisión de los gestores sobre el futuro de la organización, así como también de financiadores públicos y privados, gestores de redes sociales, investigadores, consultores, administradores públicos, entre otros stakeholders, y abre el camino para otros estudios sobre el tema.

Palabras clave: emprendimiento interno social; ciclo de vida; tercer sector.

Model of life cycle of social enterprises

This article presents a model of the life cycle of social enterprises. The primary data were obtained from interviews with founders of ten social ventures of Curitiba (PR) about the life history of the organization.

Artigo recebido em 8 jun. 2011 e aceito em 12 abr. 2012. 
The qualitative analysis identified five stages of evolution (Social Action, Association, Social Visibility, Social Network and Social Representation) with, respectively, six times of crisis that determine the transition to a later stage (Social disequilibrium, Identity, Focus, Control, Accountability and Ethics). The study reinforces the differences between social entrepreneurship and the private and justifies the differential treatment between them. The model can support the decision makers on the future of the organization, as well as public and private funders, network managers, social researchers, consultants, public administrators and other stakeholders and paves the way for further studies on the subject.

KEY WORDS: social entrepreneurship; life cycle; third sector.

\section{Introdução}

O processo empreendedor e o processo evolutivo dos seres vivos podem ser explicados por um modelo de ciclo de vida centrado na ideia de diferenciação, seleção e crescimento do nascimento ou concepção do negócio até a maturidade (Dees, 2007).

Gupta e Chin (1994) apontam que há estudos sobre o ciclo de vida para organizações desde a década de 1950, mas com enfoque primordial em organizações com fins lucrativos. Para esses autores, os modelos têm em comum o paradigma evolucionista, sob o qual as organizações naturalmente evoluem com pouca chance de regressão ou involução e com um conjunto de características diversificadas em cada estágio. O retorno a estágios anteriores é muito difícil porque, para Li (2008), ao evoluir, a organização adquire habilidades e conhecimentos de maior complexidade que se incorporam à totalidade de seus recursos, não sendo possível se desfazer deles ao passar de um estágio a outro de seu ciclo de vida. Austin e colaboradores (2006) encontraram semelhanças entre o empreendedorismo privado e o empreendedorismo social, mas também diferenças quando são observados da ótica dos recursos humanos, do contexto ambiental, do negócio e das oportunidades. Phelps e colaboradores (2007) listam 33 modelos de ciclo de vida de organizações publicados de 1967 a 2003, o que mostra ser interesse do meio acadêmico compreender como, por que e mediante quais critérios uma organização evolui, e ao mesmo tempo justifica a relevância deste estudo.

Diante do exposto, emerge a questão central desta pesquisa sobre a necessidade de se criar um modelo de ciclo de vida que represente os diversos estágios evolutivos dos empreendimentos sociais, em que cada etapa e períodos de transição entre etapas tenham características próprias e bem definidas. Alguns ciclos de vida de empreendimentos sociais foram encontrados na literatura, como o da Ashoka (Voltolini, 2004), o de Stevens (2002) e o de Sharken Simon e Donavan (2004), porém aparecem neste artigo apenas como indicador de que outros pesquisadores estudaram o tema e não como fonte de inspiração ou orientação para o modelo aqui proposto.

Este trabalho está dividido em quatro seções, além dessa introdução. Na seção 2 é apresentado um breve referencial teórico sobre empreendedorismo social. Na seção 3 são detalhados os procedimentos da pesquisa. A quarta seção foi reservada para apresentar o modelo do ciclo de vida e a última seção, para conclusões da pesquisa e recomendações para trabalhos futuros. 


\section{Empreendedorismo social}

Para Assumpção e Campos (2011), durante o período ditatorial na América Latina nas décadas de 1970 e 1980, a participação dos cidadãos em defesa de seus interesses foi fortemente condicionada à garantia de liberdades políticas. Atuava-se contra o governo e, como uma estratégia de luta, os cidadãos se organizaram em um movimento associativo formal e informal de contestação que originou o embrião do que hoje se chama organização não governamental (ONG).

No entanto, foi nos anos 1990 que a participação social em decisões antes da alçada exclusiva de governos ganhou relevância e se tornou quesito obrigatório no processo de construção e transformação da sociedade, inclusive com a alteração substancial do discurso político. Para Milani (2008), essa mudança de foco altera a função tradicional do poder público como mero prestador de serviços sociais para um papel de articulador do governo e de representantes da sociedade para coletivamente resolverem os problemas sociais.

As organizações formais oriundas da participação social apresentam uma variedade de tipologias, formas de atuação e origens. Nesse espectro incluem-se instituições religiosas, ONGs, movimentos sociais, sindicatos, instituições de ensino, empreendimentos sem fins lucrativos e fundações empresariais (Falconer, apud Albuquerque, 2006), tratadas de forma generalista como empreendimentos sociais (Shaw e Carter, 2007) na tentativa de englobar as diferenças e unificar o discurso. Silva (2010) afirma que essas organizações fazem parte do terceiro setor, chamado assim por executar ações típicas do primeiro setor (Estado) com participação autônoma, voluntária e privada, típica do segundo setor (mercado).

No meio acadêmico, entretanto, observa-se há algum tempo que não há um consenso claro sobre o que é "empreendedorismo social" e que a pesquisa nesse campo ocorre de forma um tanto marginal e pouco engajada (Nicholls, 2010). Zahra e colaboradores (2009) comungam da mesma opinião e lembram que o mesmo já acontece no domínio do "empreendedorismo", e aumenta em complexidade quando o termo "social" é incluído.

Hervieux e colaboradores (2010) contrapõem-se a isso e concluem que, apesar das muitas definições divergentes sobre empreendedorismo social na literatura, foi possível encontrar um elo entre elas. Para eles, organizações com missão social e que se valem de meios comerciais ou de negócio são, de fato, empreendimentos sociais e é isso que as une. Entendem como missão do empreendimento social criar valor social através da inovação e organização socioeconômica, fazendo uso de recursos financeiros como garantia de sustentabilidade.

\section{Procedimentos metodológicos}

Nesta seção do artigo apresentam-se os métodos para coleta de dados e de identificação das etapas do ciclo de vida de empreendimentos sociais. Este artigo caracteriza-se como uma pesquisa aplicada, qualitativa e de cunho exploratório.

O paradigma interpretativo (Morgan, 1980) norteia os procedimentos metodológicos, pois a identificação das fases foi realizada a partir dos conteúdos verbalizados pelos funda- 
dores das organizações estudadas de como entendem a trajetória histórica do empreendimento social. As respostas foram analisadas qualitativamente e foram classificados excertos que mantinham afinidade uns com outros para estabelecer padrões entre os fenômenos históricos, com a intenção de formular o modelo de ciclo de vida. A pesquisa foi construída através da história oral (Alves-Mazzotti e Gewandsznajder, 2002) contada por pessoas que acompanharam o crescimento dos empreendimentos sociais, com posterior análise e interpretação das narrativas dos informantes. Os conteúdos manifestos ou latentes foram codificados em categorias de análise, com as devidas relações entre as categorias.

O ciclo de vida de empreendimentos sociais estará impregnado da interpretação dos autores a partir dos dados coletados em campo (Briceño-León, 2003) e, por isso, mantivemonos atentos para não impor vieses de interpretação que não correspondessem aos fenômenos estudados (Alves-Mazzotti e Gewandsznajder, 2002); para manter a confiabilidade dos dados, com consistência e com descrições mais próximas o possível dos relatos.

Como forma de minimizar os efeitos do excesso de subjetividade, a pesquisa também foi amparada por uma pesquisa documental indireta - bibliográfica e dados secundários

- (Marconi e Lakatos, 2001), com consulta a literatura de referência e a documentos dos empreendimentos, em meio físico ou eletrônico (Mattar, 2005; Severino, 2000).

A pesquisa foi realizada em quatro etapas bem delineadas. Em primeiro lugar, definiuse a amostra de organizações que seriam estudadas. Na sequência, um instrumento de pesquisa foi definido e aplicado nas entrevistas. Posteriormente, segue o processo de análise dos conteúdos expressos pelos entrevistados. Os critérios de seleção priorizaram organizações com relevância e reconhecimento local, nacional e internacional, e elevado nível de profissionalização e alcance social.

Um termo de consentimento foi estabelecido com as organizações para acordar os critérios de confidencialidade das respostas por ambas as partes, garantir a lisura do processo de investigação e validar os princípios éticos que norteiam a pesquisa.

\subsection{Coleta de dados}

Um roteiro de entrevista (quadro 1) foi criado para nortear a ação do pesquisador durante os encontros agendados com os fundadores. A pergunta central e introdutória da entrevista é um convite para o entrevistado contar livremente a história da organização, da concepção da ideia do negócio até o momento atual. A opção pela entrevista semiestruturada, com perguntas abertas, serve para proporcionar a liberdade total para o entrevistado respondê-la da forma como julgar mais conveniente (Barros e Lehfeld, 2000). 
Quadro 1

\section{Roteiro de entrevista}

PERGUNTA CENTRAL:

V Como foi a trajetória desta organização desde sua fundação até os dias atuais?

PERGUNTAS COMPLEMENTARES (Pedir ao entrevistado para esclarecer os momentos e as datas em que os fatos aconteceram):

v Como surgiu a ideia de criar essa organização?

V Como foi o processo de criação do empreendimento social?

$\boldsymbol{\nabla}$ Como escolheram o público que o empreendimento social atende?

V Que características pessoais tinham/têm os fundadores?

V Os fundadores tinham/têm alguma ligação direta com a causa que o empreendimento social defende?

V Quais as dificuldades iniciais do empreendimento social? Como as superaram?

v Como é esse público? Quais suas características?

- O que a organização faz, que público atende, qual a abrangência da atuação, a forma de atuação etc.?

V Como você descreve a atuação do empreendimento social ao longo dos anos?

$\boldsymbol{\nabla}$ Como foram as alterações nos produtos/serviços ao longo dos anos?

v O empreendimento social passou por algum momento importante de crise (financeira, institucional, de relacionamento etc.)? Que tipo de crise? Como superaram esses momentos? O que aconteceu depois da crise? Como foi a atuação dos líderes nesses momentos?

V Qual a importância desses momentos para a sobrevivência da organização?

V Como avalia a situação do empreendimento social hoje?

V Como descreve a atuação das lideranças ao longo do tempo?

v Como mudou a estrutura organizacional do empreendimento social ao longo do tempo?

$\boldsymbol{\nabla}$ Como evoluiu o sistema de controles do empreendimento social?

v Como evoluiu o sistema de remuneração/recompensas ao longo dos anos?

- Como evoluíram as relações trabalhistas ao longo dos anos?

Fonte: Elaborado pelos autores.

Espera-se que as perguntas complementares sejam respondidas naturalmente, mas se não forem, o pesquisador deve inquirir o entrevistado. As perguntas foram criadas com o intuito de evidenciar sequências de ocorrências históricas que pudessem caracterizar etapas do ciclo e momentos de transição para caracterizar momentos de crise. São baseadas nos critérios de Greiner (1975) para identificar as práticas organizacionais consubstanciadas em ações, atenções e objetivos do líder ao longo dos anos; momentos de evolução e crise; mudanças na estrutura organizacional; evolução do sistema de controles; critérios de remuneração/recompensa; relações trabalhistas; entre outras. As entrevistas com fundadores das organizações devem preferencialmente ser gravadas mediante autorização prévia ou, quando não autorizadas, somente escritas pelo entrevistador. Dados secundários como registros em publicações 
internas e externas às organizações e relatórios de desempenho servem para aumentar o grau de informação sobre a situação dessas organizações e como fonte de triangulação de dados e consequente validação das respostas (Denzin e Lincoln, 2006). As entrevistas gravadas devem ser transcritas para posterior análise e classificação em categorias.

\subsection{Análise de dados}

Para a análise dos dados, foram considerados três eixos principais: o referencial teórico sobre empreendedorismo social, os relatos dos fundadores dos empreendimentos sociais e a teoria sobre ciclos de vida organizacionais. Vários modelos de ciclo de vida foram consultados, tanto os construídos para organizações privadas (Greiner, 1975; Churchill e Lewis, 1983; Scott e Bruce, 1987; Adizes, 2004; Hunter, 2005) quanto para organizações não lucrativas (Stevens, 2002; Voltolini, 2004; Sharken Simon e Donavan; 2004).

Após a transcrição das entrevistas, evidenciaram-se expressões ou palavras que permitiram nominar as fases e períodos de crise entre elas. Manteve-se a fidelidade ao que foi dito, embora se mostrasse prudente corrigir elementos de oralidade que não implicaram perda do conteúdo, com obediência ao padrão culto da língua, visto que a pesquisa buscou padrões evolutivos das organizações e não padrões estéticos ou culturais da fala dos respondentes.

O cruzamento das entrevistas convergiu para a identificação das etapas do ciclo de vida de empreendimentos sociais. A nominação das etapas emergiu de elementos da literatura, da fala dos entrevistados ou de algum termo que conseguisse abarcar o conceito que congregasse e representasse os resultados.

\section{Resultados e discussão}

Nesta seção serão apresentados os resultados da entrevista e as etapas do ciclo de vida de empreendimentos sociais. Zahra e colaboradores (2009) apontam que o paradigma do discurso sobre o empreendedorismo social gira em torno dos atributos pessoais mais elevados do empreendedor ou com foco na localidade. Os resultados deste trabalho apontam que nos estágios iniciais do empreendimento o empreendedor é investido de caráter mítico e as ações são centradas na localidade, pois é espaço onde o desequilíbrio social é vivido de forma mais intensa. Contudo, constatou-se que a organização afasta-se desses modelos à medida que evolui.

\subsection{Entrevistas}

Escolheram-se cinco instituições como amostra inicial para esta pesquisa; contudo, os resultados se mostraram insuficientes. Para ampliar o escopo, foram indicadas outras organizações para serem pesquisadas, segundo a técnica conhecida como "bola de neve". O quadro 2 apresenta os empreendimentos sociais participantes da pesquisa. 
Quadro 2

Características dos empreendimentos sociais participantes da pesquisa

\begin{tabular}{|c|c|c|}
\hline & Campo de atuação & Ano \\
\hline A & Educação popular e formação política, economia solidária. & 1981 \\
\hline B & Direitos humanos de gays, lésbicas, travestis e transexuais. & 1992 \\
\hline C & Mulheres em situação de vulnerabilidade social: pobreza, violência, saúde, educação, entre outras áreas. & 1995 \\
\hline $\mathrm{D}$ & Promoção dos direitos humanos e o acesso à educação e à saúde. & 1995 \\
\hline $\mathrm{E}$ & Proteção e assistência a mulheres e crianças em situação de vulnerabilidade social. & 1995 \\
\hline $\mathrm{F}$ & $\begin{array}{l}\text { Projetos de fomento, integração e apoio ao empreendedorismo comunitário, visando à inclusão econômica } \\
\qquad \text { e social através da geração de trabalho, renda e desenvolvimento local. }\end{array}$ & 2001 \\
\hline G & $\begin{array}{l}\text { Utilização de animais com fins terapêuticos. Atendimento direcionado a instituições: asilos, lares para } \\
\text { crianças, escolas com crianças com dificuldade de aprendizagem, entre outros. }\end{array}$ & 2003 \\
\hline $\mathrm{H}$ & Presta serviços médico-hospitalares. Mantenedora de uma casa de saúde. & 2003 \\
\hline I & Direitos humanos de travestis e transexuais. & 2004 \\
\hline J & Inclusão de pessoas com deficiência no mercado de trabalho. & 2005 \\
\hline
\end{tabular}

Fonte: Elaborado pelos autores.

Observou-se que nos empreendimentos sociais, diferentemente dos privados, as entrevistas revelaram que os momentos históricos são carregados de significado social e coletivo. As falas sugeriram que o empreendedor (ou grupo empreendedor) está intimamente condicionado ao viés coletivo da causa social. Os nomes de cada etapa e das transições entre etapas foram obtidos da análise do conteúdo das entrevistas em conjunto com a literatura de referência. Na nominação da primeira fase, por exemplo, foram extraídos trechos das falas dos entrevistados e da literatura de referência que apontam para a ação social direta para solucionar os problemas sociais (ver figura 1).

Constatou-se nas entrevistas que os motivos declarados para o início da atividade empreendedora são externos, mobilizados pela observação e pela sensibilidade diante dos fatos sociais, mas com motivação interna, como em Greiner (1975). A atividade empreendedora mostrou-se como o resultado da construção social do indivíduo mediada pela interação entre ele, a rede social em que está inserido e o meio físico, como já observado por Sørensen e colaboradores (2007). 
Figura 1

Nominação das etapas do ciclo de vida de empreendimentos sociais

"Comecei do nada [...] o primeiro passo foi pegar a cachorra e ir ao Instituto São Vicente de Paula (instituição para pessoas da terceira idade) [...] Uma pessoa foi falando pra outra, a notícia foi se espalhando". (Fundador do Empreendimento Social G)

"As reuniões eram uma vez por semana no sábado à noite e conforme as pessoas que vinham participando a conversa ia para um lado, depois pro outro" [...] (Fundador do Empreendimento Social B)

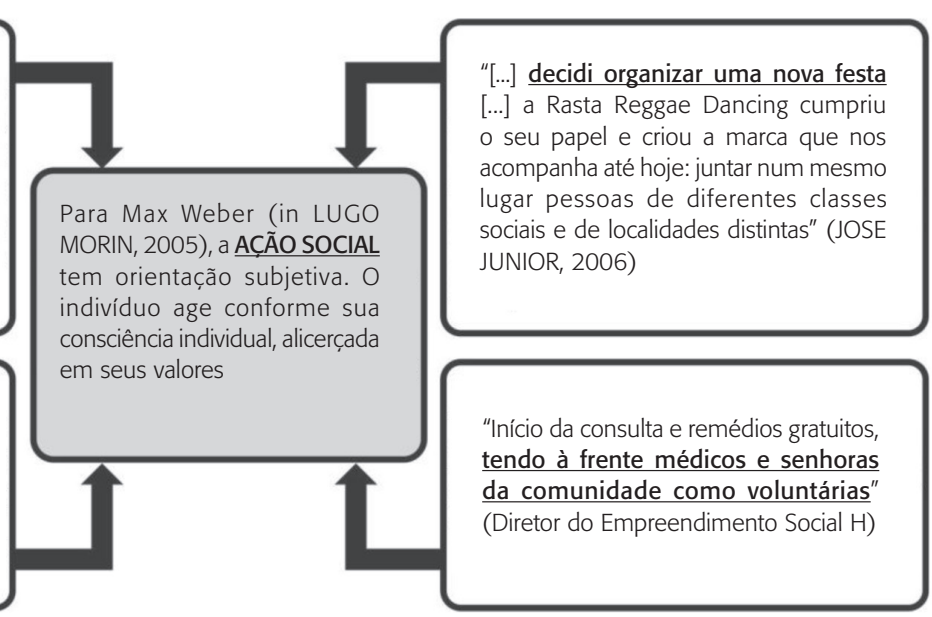

[...] decidi organizar uma nova festa Ta Reggae Dancing cumpriu lugar pessoas de diferentes classes sociais e de localidades distintas" (JOSE Para Max Weber (in LUGO

icio da consulta e remédios gratuitos,

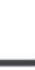

Fonte: Elaborado pelos autores.

\subsection{Ciclo de vida de empreendimentos sociais}

A presente seção descreve as etapas do modelo de ciclo de vida de empreendimentos sociais.

\subsubsection{Ação social}

A ação social tem orientação subjetiva, conforme assinalado por Max Weber (Lugo Morin, 2005). O indivíduo age de acordo com sua consciência, porém alicerçado em valores pessoais. Esse caráter subjetivo foi observado nas falas dos entrevistados. Evidenciou-se que os empreendedores sociais movem-se inicialmente pelo "problema social e a busca de soluções" (Ashoka-Mckinsey, 2001). Ao estudar a biografia de grandes líderes da humanidade, Parameshwar (2006) constatou que esses indivíduos se mobilizaram com o intuito de revelar práticas de dominação e questionar a ideologia dominante. Também foram inspirados em conselhos e condutas de parentes, professores, cientistas, personagens históricos, entre outros. Há também a motivação pela identificação com o sofrimento alheio ou redefinição de verdades próprias para colocar-se em prol de dirimir o sofrimento dos outros. Normalmente, não há de imediato a formalização legal do empreendimento como uma empresa formalmente estabelecida nos termos da lei. Mais importante é trazer soluções para os problemas sociais. Nesse sentido, a gestão do empreendimento é relegada a um segundo plano. 
A gestão do empreendimento é rudimentar e as despesas da organização são custeadas pelos fundadores, por seus parentes mais próximos ou por alguns poucos simpatizantes da causa. Um trecho extraído do primeiro folder do empreendimento B, convidando as pessoas a contribuírem para a causa, mostra claramente isso: “(...) somos um grupo informal em fase de formação. (...) sua contribuição poderá ser feita com material de escritório, (...) ajuda financeira ou doações em livros".

O empreendedor social figura como promotor e agente principal das ações sociais do empreendimento e normalmente é alguém intimamente ligado ao problema social. A ação empreendedora neste estágio não tem intermediários. É feita diretamente pelos voluntários (quando existem) para as pessoas que sofrem com o problema e com elevado envolvimento emocional. Lezana e Tonelli (2004) afirmam que os empreendedores obtêm benefícios de meios incertos motivados por suas necessidades, desequilíbrios ou déficits, gerados internamente e não pelo meio externo. Também há ressonância nas palavras de Schumpeter (1982) de que os indivíduos produzem para a satisfação de suas necessidades, mediadas pela condição externa. Os trechos a seguir, extraídos das entrevistas e da literatura, ilustram o que foi dito.

A crise de identidade ao fim dessa etapa manifesta-se na constatação de que mais pessoas precisam de ajuda e que o empreendedor não pode se manter somente com a energia e recursos próprios para continuar com a ação social. Não é mais possível dar e obter segurança e alívio de suas dores e tensões próprias e de terceiros, bem como a satisfação de necessidades somente na troca subjetiva entre os que compartilham a causa. Essa fase de transição foi nominada como crise de identidade porque as ansiedades e os medos no mundo moderno impelem as pessoas a se unirem em grupos que comungam de uma identidade, porém a busca por essa identidade não deixa de dividir e separar (Bauman, 2003). Por isso, conforme assinalado por James e Arroba (2005), o empreendedor social deve ampliar a capacidade de observação do contexto e ver as situações de forma isenta e ampla, identificar e compreender seus próprios sentimentos. Dessa forma, não é possível mais utilizar-se do empreendimento somente como objeto de alívio para suas próprias tensões diante da situação social desfavorável.

\subsubsection{Associação}

Os recursos próprios e as doações voluntárias não suprem as necessidades do empreendimento. O acesso a novos recursos se dá por meio de fontes de financiamento de origem privada e pública. O tempo de duração da fase anterior para esta é específico para cada organização e condicionado ao perfil e capacidade de compreensão do contexto por parte do empreendedor social. A constatação do início desta fase é que o empreendimento não pode ser levado adiante sem os recursos financeiros e, neste momento, qualquer fonte de recursos é bem-vinda. Contudo, para a maioria dos financiadores, a formalização do empreendimento é condição sine qua non.

Os empreendedores não podem mais atuar sozinhos, pois a formalização como associação requer um mínimo de sete pessoas, segundo a legislação brasileira. A conclusão desta 
pesquisa é que a saída mais comum é o empreendedor social se associar a outros pares somente para atender ao requisito legal, mas que, habitualmente, continua como figura central do empreendimento. Embora incipiente em termos organizacionais e com recursos humanos pouco especializados, o empreendedor começa a vislumbrar a possibilidade de crescimento e de transformação real da realidade social.

Associação foi o termo escolhido para nominar esta fase porque a união de indivíduos que comungam da luta pela causa social, mesmo que somente no âmbito formal, é a propulsora do crescimento do empreendimento durante a segunda etapa. A formalização restringe-se inicialmente às exigências legais, especialmente quanto aos requisitos para criação da organização e prestação de contas, e esta última é habitualmente relegada a um segundo plano.

Os projetos de financiamento públicos e privados remuneram a organização e os recursos humanos, enquanto os convênios estão vigentes. Os associados, por vezes marginalizados, estigmatizados, desempregados ou com subempregos, têm nas atividades dos projetos uma forma de geração de renda e de inserção no mercado de trabalho. Esses projetos são acompanhados, em maior ou menor grau, pelos financiadores mediante indicadores preestabelecidos na fase de elaboração do projeto. O principal financiador de projetos sociais no Brasil é o poder público, pois através dos projetos os governantes conseguem um alcance maior de suas ações, menos custos operacionais para o Estado e angariam benefícios políticos por estarem intimamente ligados às necessidades da população (Luksetich, 2008).

Os critérios de avaliação dos financiadores públicos são puramente burocráticos, mediante garantias e contratos com demonstração da capacidade de cumprir com ações acordadas (Carman, 2009). Os financiadores privados focam o monitoramento em resultados palpáveis e mensuráveis dos projetos sociais, principalmente naqueles nos quais seja possível identificar relevante impacto social positivo e com eles fazer marketing social. Os gestores se capacitam na elaboração de projetos, de relatórios de desempenho e no monitoramento de projetos, pois a boa prestação de contas resulta em novos financiamentos ou na renovação dos antigos.

A falta de foco dos projetos é o ponto alto da crise ao final desta etapa do ciclo de vida. Diante do universo limitado de possibilidades de fontes de financiamento, há uma competição acirrada por recursos, e os projetos, na maioria, são encaminhados aos financiadores potenciais sem considerar as competências da organização e seus propósitos originais. Nota-se o desgaste das relações internamente e a imagem do empreendimento perante os financiadores começa a ficar comprometida.

\subsubsection{Visibilidade social}

A crise de foco da etapa anterior faz a organização rever seu modo de operação e neste momento o empreendedor compreende a gestão participativa como forma de se manter ativa e com competência para captar, gerar e gerenciar recursos financeiros, materiais e humanos. A ajuda externa é comumente requisitada nesta etapa para orientar o alinhamento da 
organização com um foco bem definido, com a perspectiva de direcionar esforços em prol da eficácia organizacional. Descobre-se que a ação social assistencialista é importante, necessária em alguns casos, ameniza as consequências do problema social, mas não combate as causas.

Pontos fortes e fracos são identificados e objetivos organizacionais são compartilhados. As ações, planejadas e eficazes, proporcionam resultados positivos, principalmente em termos de visibilidade, jamais experimentados anteriormente. O empreendedor desloca-se da figura de provedor e agente para começar a construir uma imagem com contornos mais subjetivos, mas que o eleva a um posto de reconhecimento social e o mostra como alguém competente e confiável para atacar o problema social.

Essa nova posição o transforma em interlocutor da organização perante os stakeholders e no principal mobilizador de recursos. Torna-se alguém a ser seguido pelos pares, respeitado pelas pessoas que sofrem com o problema social e reconhecido pelos financiadores, poder público e sociedade em geral.

Nesta etapa do ciclo de vida, os diferentes recursos são conquistados, utilizados de forma eficiente e eficaz, com parcerias fortes e com fontes alternativas de receita, como preconiza Albuquerque (2006). Financiamentos deixam de ser somente buscados e podem ser ofertados diretamente pelos financiadores em reconhecimento pelo trabalho bem feito e pela visibilidade social alcançada. Esse fato é mais difícil de acontecer quando a população atendida ou o problema social é dotado de forte estigma e preconceito social, como profissionais do sexo, usuários de drogas, travestis e transexuais e detentos em presídios. Financiadores privados habitualmente não gostam de ver suas marcas associadas a esses públicos porque isso pode criar uma imagem negativa perante os clientes.

O empreendedor desloca sua atenção e atuação no ambiente externo, promovendo a organização e a defesa da causa, e começa a assumir a postura de um líder social na comunidade em que atua. Alguns, graças ao papel disseminador de redes sociais e por influência da mídia em geral, alçam mais rapidamente esse status diferenciado, ampliam sua rede de contatos e de influência na sociedade. Passam a ser requisitados para eventos educacionais, sociais e políticos, convidados para entrevistas e consultados sobre os fatos que interferem ou são inerentes ao problema social que o empreendimento combate.

Contudo, a realidade social não é mudada, mas apenas torna-se mais visível. Em algumas situações pontuais, mediante a capacidade de articulação política e a mobilização social do empreendedor, as ações atingem excelentes resultados, porém problemas arraigados na estrutura da sociedade ou na legislação vigente ainda não estão ao alcance do poder de solução da organização. O empreendedor social sente-se incapaz de mudar a situação.

Os projetos, antes essencialmente de promoção da causa e de assistência social, também se voltam para a articulação social e política; controle social; promoção de direitos humanos, com vistas à ampliação do espectro de direitos conquistados e de sua defesa quando há risco de violação. No fim desta etapa, o empreendedor percebe e admite que a organização sozinha não consegue interferir em problemas estruturais da sociedade e vislumbra que a aliança com outros representantes que combatem o mesmo problema social é a alternativa mais viável. 
Contudo, para ultrapassar a fase anterior, deverá questionar a si e à própria organização como lócus de controle interna e externamente.

Lidar com a crise de controle passa pelo compartilhamento do poder para planejar e conduzir a organização, delegando esse papel aos colaboradores que neste momento já possuem competência e que desejam ser protagonistas em arenas que até o momento foram somente do empreendedor. Surge o impasse de ceder privilégios e poder para os colaboradores e se tornar menos importante, ou manter o controle atual e deixar tudo como está. Não mudar pode desencadear no corpo funcional uma insatisfação crescente e o desejo de se desvincular da organização. Os colaboradores não desejam mais ser remunerados por projetos, pois preferem situação de maior estabilidade, com remuneração fixa e dentro dos requisitos de mercado e contrato de trabalho permanente.

\subsubsection{Rede Social}

Uma alternativa para a crise da etapa anterior é estimular os colaboradores a fundarem outras organizações e trabalharem conjuntamente. Também podem buscar outras organizações que atuam no mesmo segmento e em rede construir uma rede de poder com objetivos convergentes. Para Pereira e Pedrozo (2005), essa alternativa facilita a obtenção de recursos importantes que não estão à sua disposição enquanto a organização atuar sozinha e, no caso dos empreendimentos sociais, também fortalece o movimento social em prol de mudanças mais substanciais no quadro social, político e econômico. Contudo, dependendo da área de atuação, do perfil dos empreendedores sociais e do estágio de desenvolvimento da organização, a construção da rede pode ser mais difícil. Tyszler (2007) mostra as dificuldades de atuação em rede dos empreendimentos sociais que usam a arte como instrumento de melhoria das condições sociais de crianças e jovens. $\mathrm{O}$ acesso a informações que antes eram privilégio de um grupo restrito cria na rede social uma infinidade de novas oportunidades para atuar e se beneficiar dessa proximidade e, consequentemente, o fortalecimento de laços de poder (Granovetter, 1995).

As redes sociais formais, virtuais ou presenciais constituem-se a partir da interdependência e de pontos de vista, objetivos e regras compartilhados, podendo constituir-se de forma legal (Egger, 2007). Dentro dessas redes, organizam-se encontros para troca de informações e experiência. Na rede podem fazer parte organizações que estão em estágios do ciclo de vida mais atrasados como membros associados, porém com menor representatividade. A participação em conselhos consultivos, diretoria (quando é formal), mediação, organização e gerenciamento de fóruns de discussão, representação em eventos, assinaturas de acordos, entre outras funções, são designadas àquelas com maior experiência e representatividade.

O empreendimento social expande seus limites tanto em possibilidades de ação quanto do poder de representação, mas que podem representar certo afastamento da esfera de atuação local. A notoriedade alcançada na esfera local e regional proporciona maior adesão à causa, bem como a influência de parte dos empreendedores dentro e fora da rede. As decisões da 
organização são atreladas e validadas na rede social. O poder do empreendedor social amplia, porém fragmenta-se entre os pares da rede. A articulação política do empreendedor social começa a ser exigida e tem de ser explorada ao máximo, pois a interlocução dentro e fora da rede torna-se fundamental.

A crise ao fim desta etapa origina-se justamente na fragmentação de poder, em que os resultados bons e ruins são da rede ou, simbolicamente, são da causa. Não há como identificar responsáveis nem para o bem e nem para o mal. Por esse motivo nomeou-se esta crise como de responsabilização (accountability), resultante da horizontalidade das relações de poder em uma rede e da (in)capacidade do empreendedor de lidar com os entraves políticos, sociais e econômicos que isso causa.

A crise de responsabilização ao final desta etapa também se fortalece no estreitamento e na relação por vezes nebulosa com financiadores públicos ou privados. Atuar em programas sociais de vulto como extensões dos governos e o recebimento de grandes somas de dinheiro tornam-se objeto de ceticismo inclusive no meio acadêmico, como foi observado por Brockington e Scholfield (2010) nas grandes organizações que atuam na área ambiental. Lavalle e Castello (2008) vão além ao questionar a qualidade e a legitimidade em representar aqueles em nome dos quais se prega um discurso carregado de altruísmo e com palavras de ordem em defesa da sociedade.

\subsubsection{Representatividade social}

Na última etapa identificada neste estudo, o reconhecimento e a representatividade atingem níveis elevados para a organização e para seus líderes. Essa etapa foi descrita apenas a partir da literatura de referência. Não houve na amostra qualquer organização com esse elevado nível de desenvolvimento. Nessa fase, a organização ganha tamanho nível de notoriedade que sua influência pode extrapolar os limites do país onde está sediada. As ações têm ressonância na mídia, com forte impacto na opinião pública. No início do século XXI, os empreendimentos transnacionais empregavam cerca de 20 milhões de pessoas, aglutinavam grandes somas de recursos de fontes diversas com sofisticadas estruturas organizacionais. Conseguem influenciar o comportamento e oferecem expertise em assuntos específicos para vários governos, com elevado apoio da opinião pública internacional (Matias, 2006).

Como exemplos desse tipo de organização têm-se o Greenpeace, com foco de atuação no meio ambiente (Greenpeace, s.d.); a organização Médicos sem Fronteiras, com cuidados de saúde e ajuda humanitária, independentemente de nacionalidade, credo, raça ou regime de governo (MSF, s.d.) e a Anistia Internacional, na defesa de direitos humanos (Anistia Internacional, s.d.). No Brasil, um dos exemplos mais notórios, com atuação em diversos países da África, Ásia e América do Sul, é a Pastoral da Criança, com ações de combate à fome e à desnutrição infantil (CNBB, s.d.). Dada a contemporaneidade desta etapa, não é possível evidenciar a crise ao seu final, mas apenas deduzir o que pode ocorrer, partindo de questionamentos e contribuições de autores que examinam e discutem o atual modelo de gestão das 
organizações transnacionais. Burns e Lemoyne (2007), por exemplo, apontam a elevada crítica dos cientistas sociais quanto à eficácia de ONGs ambientalistas transnacionais na defesa e promoção de ações ambientais e na mudança do comportamento dos indivíduos.

Uma possível crise ética é sinalizada ao final da última etapa do ciclo de vida de empreendimentos sociais. A ética relaciona-se, nesse caso, com os aspectos mais elevados da atuação do empreendimento social na sociedade, ou a prática "do que é certo e bom", como afirmam Hisrich e Peters (2004:99). Entra em questão o conjunto de valores que movem os empreendedores sociais no processo de transformação da sociedade, de promoção de valores importantes e cruciais para o desenvolvimento das liberdades substantivas (Sen, 2000), e de se consolidar como referência no movimento social em que atua.

Para Northouse (2004), o papel do líder ético envolve um conjunto de ações interconectadas que são o respeito aos outros, a vontade de servir, a demonstração de justiça, manifestação de honestidade e a construção da comunidade. O altruísmo do comportamento ético manifesta-se na busca do bem-estar geral, no tratamento equânime e igualitário, e garantindo as liberdades individuais. Segundo Sen (2000), as liberdades do indivíduo dividem-se em políticas, de oportunidades sociais, transparência, facilidades econômicas e segurança protetora. Ainda estende o conceito para incluir que ser livre é uma condição para avaliar e modificar sua realidade como ente transformador da sociedade.

\subsection{0 modelo}

O modelo de ciclo de vida de empreendimentos sociais assemelha-se aos modelos para organizações privadas descritos na literatura, principalmente ao de Greiner (1975). O modelo simplificado é apresentado na figura 2.

Contudo, há diferenças substanciais nas características de cada etapa e nas motivações e no significado de cada fase de transição/crise. Do modelo de Greiner (1975) mantêm-se as premissas de que:

a) as etapas subsequentes são determinadas pelas etapas anteriores e pelos períodos de transição sobre uma linha de tempo;

b) existência de uma linha evolutiva da criação à maturidade que pode ser mais ou menos acentuada de uma organização para outra;

c) a participação do empreendedor nas atividades operacionais diminui ao longo da vida organizacional, quando é gradualmente delegada a seus subordinados;

d) o nível de complexidade da organização e da estrutura de poder aumenta ao transpor as fases;

e) as crises ou períodos de transição são originados em fatores internos. 
Figura 2

Ciclo de vida de empreendimentos sociais

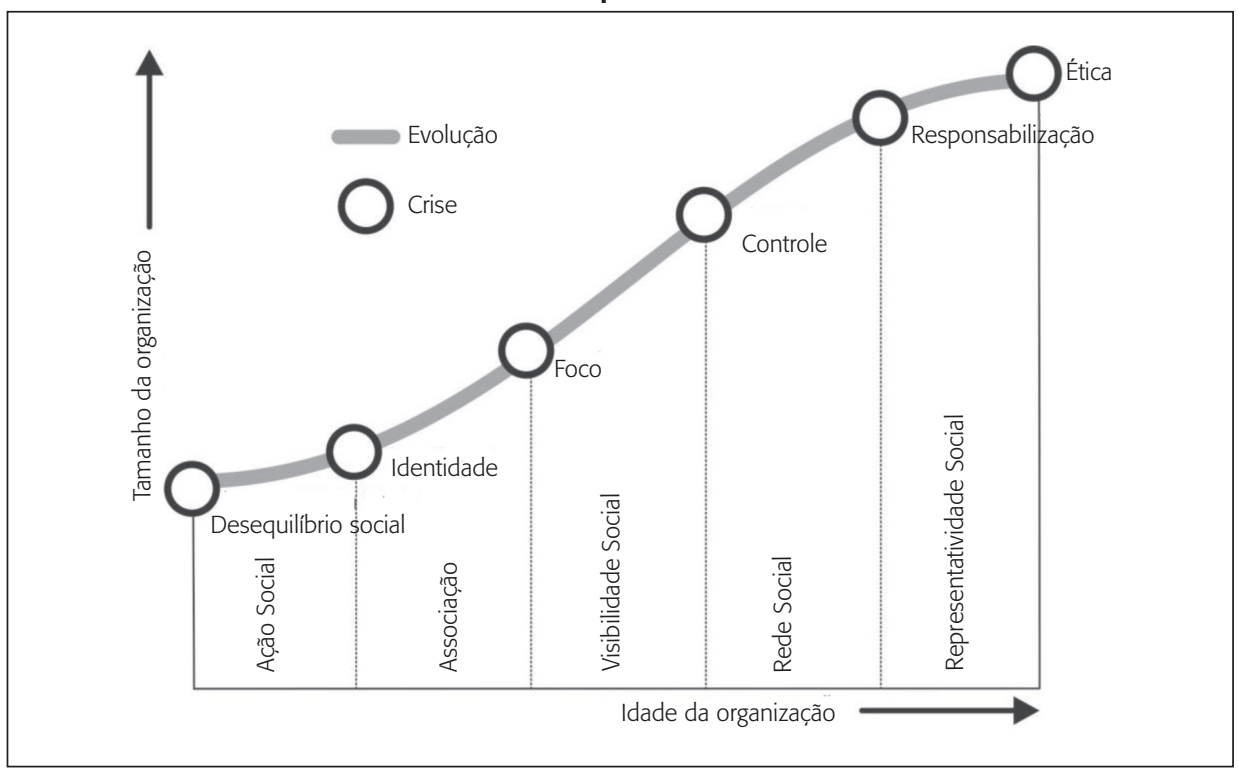

Fonte: Elaborado pelos autores.

Quanto às diferenças entre os modelos de ciclo de vida para empreendimentos privados observou-se que:

a) nas primeiras fases do ciclo de vida é comum não haver alterações significativas do quadro de pessoal, pois as ações são muito centralizadas na figura do empreendedor social. A estrutura da organização, mesmo quando assume etapas transnacionais, ainda mantém um forte componente de centralização. A figura mítica do fundador perpetua-se principalmente quando é alguém diretamente ligado à causa;

b) Nos relatos, identificou-se que as ações do empreendedor são justificadas com expressões relacionadas com a caridade, amor ao próximo, indignação com as questões sociais, carregados de afetividade. Essa constatação difere da racionalidade com que são tratados os resultados econômicos dos empreendimentos lucrativos (Baruch e Ramalho, 2006). À medida que as etapas se sucedem, a subjetividade inicial é gradualmente substituída por tecnologias, métodos, planejamento, entre outras do mundo corporativo lucrativo, tendendo a maior racionalidade conforme a empresa avança nas etapas (ver figura 3); 
Figura 3

\section{Racionalidade e assistencialismo nos empreendimentos sociais}

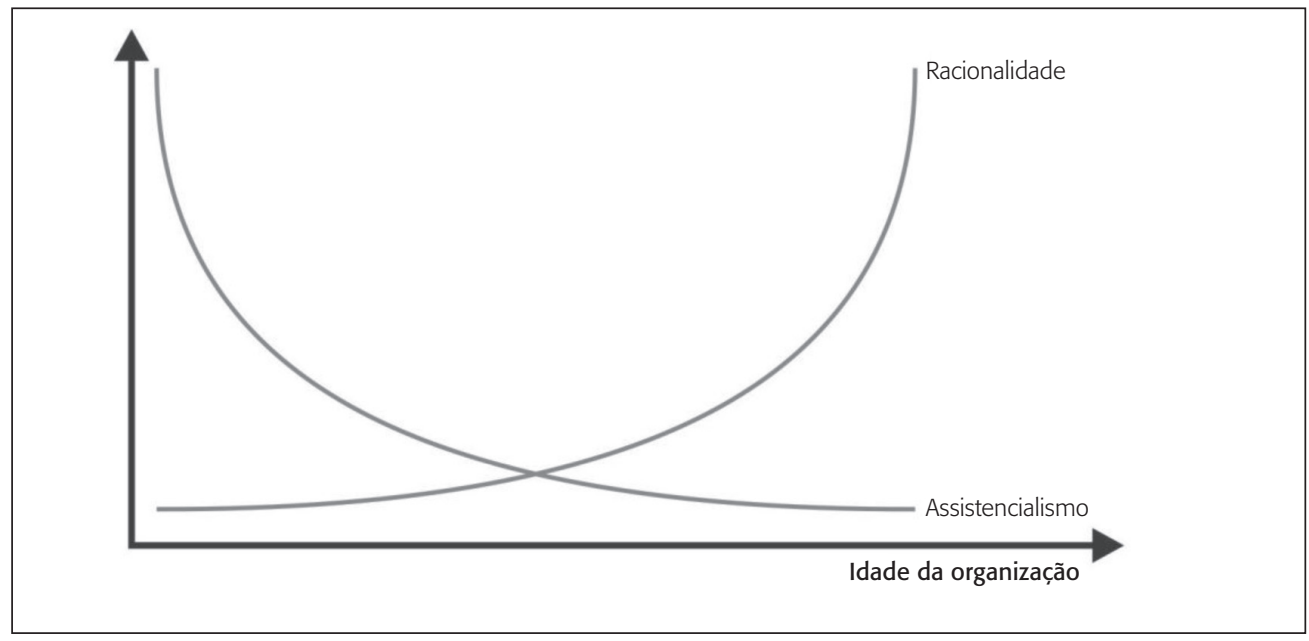

Fonte: Elaborado pelos autores.

c) a ação social direta ou puramente assistencialista nas primeiras fases é gradualmente substituída pela ação voltada para a mudança do contexto social, com atuação mais na esfera política e institucional. Isso não quer dizer que a organização deixe de assistir e tratar quando isso faz parte de sua vocação. Tome-se o caso da Cruz Vermelha, por exemplo, que age na assistência emergencial de toda natureza em todo o planeta e nunca deixou de fazê-la desde sua fundação em 1919. Contudo, basta consultar a agenda pública desta organização (CVB, s.d.) e constatar sua articulação com segmentos do governo, com instituições tecnológicas e com outros atores da esfera social. Essas ações vão muito além da assistência às vítimas, mas todas convergem para a missão organizacional de prevenir e aliviar o sofrimento humano tanto quanto para a atividade de assistência;

d) nas fases iniciais, as atividades empreendedoras centram-se no ambiente local. $O$ embate direto com o problema social é central e direciona a energia e os recursos do empreendimento e, por isso, essas etapas possuem forte caráter subjetivo e emocional. $\mathrm{O}$ afastamento da ação puramente local é evidente ao passar do tempo. Os empreendedores envolvidos direta e emocionalmente com a causa tendem a se manter nas etapas iniciais por mais tempo.

O quadro 3 sintetiza as características de cada uma das etapas segundo os critérios de atenção da direção, estrutura da organização, estilo da alta direção, sistema de controle e ênfase na direção de recompensas. 
Quadro 3

Características das etapas do ciclo de vida de empreendimentos sociais

\begin{tabular}{|c|c|c|c|c|c|}
\hline CRITÉRIO & Ação Social & Associação & $\begin{array}{c}\text { Reconhecimento } \\
\text { Social }\end{array}$ & Rede Social & $\begin{array}{c}\text { Representatividade } \\
\text { Social }\end{array}$ \\
\hline $\begin{array}{l}\text { Atenção da } \\
\text { direção }\end{array}$ & $\begin{array}{l}\text { Enfrentamento do } \\
\text { problema social }\end{array}$ & Angariar recursos & $\begin{array}{l}\text { Conseguir adesão } \\
\text { à causa e divulgar } \\
\text { resultados }\end{array}$ & Alianças & $\begin{array}{l}\text { Promoção e defesa } \\
\text { de valores afeitos à } \\
\text { humanidade como um } \\
\text { todo. Transformação da } \\
\text { sociedade }\end{array}$ \\
\hline $\begin{array}{l}\text { Estrutura da } \\
\text { organização }\end{array}$ & Informal/Incipiente & $\begin{array}{c}\text { Formal, } \\
\text { centralizada, } \\
\text { orientada pelos } \\
\text { projetos }\end{array}$ & $\begin{array}{c}\text { Centralizada e } \\
\text { geográfica, conforme } \\
\text { planejamento } \\
\text { estratégico, com } \\
\text { alguma delegação }\end{array}$ & $\begin{array}{l}\text { Centralizada, } \\
\text { com atuação } \\
\text { através de } \\
\text { redes }\end{array}$ & $\begin{array}{l}\text { Escritório central com } \\
\text { ramificações nos níveis } \\
\text { regional, nacional e/ou } \\
\text { internacional }\end{array}$ \\
\hline $\begin{array}{l}\text { Estilo da alta } \\
\text { direção }\end{array}$ & $\begin{array}{c}\text { Assistencialista, com } \\
\text { orientação subjetiva e } \\
\text { emocional }\end{array}$ & Controlador & $\begin{array}{l}\text { Líder social e } \\
\text { promotor social }\end{array}$ & $\begin{array}{c}\text { Articulador } \\
\text { social, político } \\
\text { e econômico }\end{array}$ & Midiático, influenciador \\
\hline $\begin{array}{l}\text { Sistema de } \\
\text { controle }\end{array}$ & $\begin{array}{l}\text { Subjetivo, baseado } \\
\text { em observações e } \\
\text { sentimentos }\end{array}$ & $\begin{array}{c}\text { Plano de ação e } \\
\text { orçamento dos } \\
\text { projetos para } \\
\text { financiadores } \\
\text { públicos e } \\
\text { relatórios de } \\
\text { desempenho } \\
\text { para os privados }\end{array}$ & $\begin{array}{c}\text { Relatórios e } \\
\text { indicadores de } \\
\text { desempenho da } \\
\text { organização e } \\
\text { indicadores sociais } \\
\text { locais }\end{array}$ & $\begin{array}{c}\text { Relatórios e } \\
\text { indicadores de } \\
\text { desempenho } \\
\text { da rede e } \\
\text { indicadores } \\
\text { sociais } \\
\text { regionais }\end{array}$ & $\begin{array}{l}\text { Elevado uso de } \\
\text { tecnologia de } \\
\text { informação }\end{array}$ \\
\hline $\begin{array}{l}\text { Ênfase da } \\
\text { direção em } \\
\text { recompensas }\end{array}$ & $\begin{array}{l}\text { Busca da identidade, } \\
\text { recompensa divina, } \\
\text { imagem social, entre } \\
\text { outras de caráter } \\
\text { subjetivo }\end{array}$ & $\begin{array}{l}\text { Remuneração } \\
\text { por projetos, } \\
\text { quase sempre } \\
\text { sem vínculo } \\
\text { empregatício }\end{array}$ & $\begin{array}{l}\text { Ganho de poder, } \\
\text { profissionalização, } \\
\text { qualificação e registro } \\
\text { como funcionário }\end{array}$ & $\begin{array}{l}\text { Notoriedade. } \\
\text { Vantagens } \\
\text { políticas e } \\
\text { financeiras }\end{array}$ & $\begin{array}{l}\text { Influência social, } \\
\text { política e financeira }\end{array}$ \\
\hline
\end{tabular}

Fonte: Elaborado pelos autores.

O reconhecimento do atual estágio de desenvolvimento de um empreendimento social pode servir para avaliar o grau de desenvolvimento organizacional e subsidiar a decisão do grupo gestor, bem como de financiadores privados e públicos, administradores de redes de organizações do terceiro setor, pesquisadores, governantes, entre outros.

\section{Conclusões}

O ciclo de vida de empreendimentos sociais que é apresentado neste artigo é um modelo representativo tanto das etapas do desenvolvimento do empreendimento quanto da atuação do empreendedor social. Considerou-se a transformação dos empreendimentos desde seu nascimento até sua maturidade, sob a metáfora da organização como ser vivo. 
Foram identificadas cinco etapas do ciclo (Ação Social, Associação, Visibilidade Social, Rede Social e Representatividade Social) permeadas por seis momentos de crise na transição entre etapas (Desequilíbrio Social, Identidade, Foco, Controle, Responsabilização e Ética), cada uma com características próprias e apresentadas em cinco categorias de análise (Atenção da direção; Estrutura da organização; Estilo da alta direção; Sistema de controle; Ênfase da direção em recompensas). As etapas do modelo mostraram-se mais complexas e com descrições mais elaboradas das características de cada etapa do que os modelos de ciclo de vida de empreendimentos sociais encontrados na literatura e já mencionados na introdução deste artigo. Contudo, é fundamental verificar a aderência do modelo em empreendimentos sociais diferentes daqueles participantes desta pesquisa e verificar se o mesmo descreve a evolução da organização da mesma forma. Como esta pesquisa restringiu-se a empreendimentos sociais sediados em Curitiba (PR), sul do Brasil, deve-se aplicá-la em outras regiões para compreender se o resultado não foi contaminado por aspectos socioculturais regionais.

Estudos futuros podem se dedicar a criar um instrumento para medir e avaliar em qual fase uma organização está atualmente e em que momento se moverá para o estágio subsequente. Esse instrumento deverá minimizar a ambiguidade de termos característicos das fases e quantificá-los.

\section{Referências}

ADIZES, Ichak. Gerenciando os ciclos de vida das organizações. São Paulo: Prentice Hall, 2004.

ALBUQUERQUE, Antonio C.C. Terceiro setor: história e gestão de organizações. São Paulo: Summus, 2006.

ALVES-MAZZOTTI, Alda J.; GEWANDSZNAJDER, Fernando. O método das ciências naturais e sociais: pesquisa quantitativa e qualitativa. São Paulo: Pioneira Thomson Learning, 2002.

ANISTIA INTERNACIONAL. s.d. Disponível em: <www.br.amnesty.org>. Acesso em: maio 2011. ASHOKA-MCKINSEY. Empreendimentos sociais sustentáveis: como elaborar planos de negócios para organizações sociais. São Paulo: Petrópolis: 2001.

ASSUMPÇÃO, Jairo J.; CAMPOS, Lucila M.S. Avaliação de projetos sociais em ONGs da Grande Florianópolis: um estudo sobre modelos relacionados ao foco de atuação. Revista de Administração Pública, Rio de Janeiro, v. 45, p. 209-242, 2011.

AUSTIN, James et al. Social and commercial entrepreneurship: same, different, or both? Entrepreneurship Theory and Practice, v. 30, n. 1, p. 1-22, 2006.

BARROS, Aidil J.S.; LEHFELD, Neide A.S. Fundamentos de metodologia científica. São Paulo: Makron, 2000.

BARUCH, Yehuda; RAMALHO, Nelson. Communalities and distinctions in the measurement of 
organizational performance and effectiveness across for-profit and nonprofit sectors. Nonprofit and Voluntary Sector Quarterly, v. 35, n. 1, p. 35-39, Mar. 2006.

BAUMAN, Zygmunt. Comunidade: a busca por segurança no mundo atual. Rio de Janeiro: Jorge Zahar Editor, 2003.

BRICEÑO-LEÓN, Roberto. Quatro modelos de integração de técnicas qualitativas e quantitativas de investigação nas ciências sociais. In: GOLDENBERG, Paulete (Org.). O clássico e o novo: tendências, objetos e abordagens em ciências sociais e saúde. Rio de Janeiro: Fiocruz, 2003.

BROCKINGTON, Dan; SCHOLFIELD, Katherine. The work of conservation organisations in subSaharan Africa. The Journal of Modern African Studies, v. 48, n. 1, p. 1-33, 2010.

BURNS, Thomas J.; LEMOYNE, Terri. Como os movimentos ambientalistas podem ser mais eficazes: priorizando temas ambientais no discurso político. Ambiente \& Sociedade, v. 10, p. 61-82, 2007.

CARMAN, Joanne G. Nonprofits, Funders, and Evaluation. The American Review of Public Administration, v. 39, n. 4, p. 374-390, 2009.

CHURCHILL, Neil; LEWIS, Virginia. The five stages of small business growth. Harvard Business Review, v. 61, n. 3, p. 30-39, May/June 1983.

CNBB. Pastoral da Criança. O que fazemos. s.d. Disponível em: <www.pastoraldacrianca.org>. Acesso em: maio 2011.

CVB. Cruz Vermelha Brasileira. Agenda pública. s.d. Disponível em: <www.cruzvermelha.org.br> . Acesso em: maio 2011.

DEES, J. Gregory. Taking social entrepreneurship seriously. Society, v. 44, n. 3, p. 24-31, 2007.

DENZIN, Norman K.; LINCOLN, Yvonna. S. O planejamento da pesquisa qualitativa: teorias e abordagens. Porto Alegre: Artmed, 2006.

EGGER, Urs K. Work the Net: um guia de gerenciamento para redes formais. Rio de Janeiro: GTZ, 2007.

GRANOVETTER, Mark S. Getting a job: a study of contacts and careers. Chicago: University of Chicago Press, 1995.

GREENPEACE. Origens do Greenpeace. s.d. Disponível em: <www.greenpeace.org/brasil/quemsomos/>. Acesso em: maio 2011.

GREINER, Larry E. Evolução e revolução no desenvolvimento das organizações. Biblioteca Harvard de Administração de Empresas, n. 14, p. 3-11, 1975.

GUPTA, Yash P.; CHIN, David C.W. Organizational life cycle: a review and proposed directions for research. The Mid-Atlantic Journal of Business, v. 30, n. 3, p. 269-294, Dec. 1994.

HERVIEUX, Chantal; GEDAJLOVIC, Eric; TURCOTTE, Marie-France B. The legitimization of social entrepreneurship. Journal of Enterprising Communities, v. 4, n. 1, p. 37-67, 2010.

HISRICH, Robert D.; PETERS, Michael P. Empreendedorismo. 5. ed. Porto Alegre: Bookman, 2004. 
HOROCHOVSKI, Rodrigo R. Associativismo civil e Estado: um estudo sobre organizações não governamentais (ONGs) e sua dependência de recursos públicos. EmTese, Florianópolis, v. 1, n. 1, p. 109-127, 2003.

HUNTER, Ian. Risk, persistence and focus: a life cycle of the entrepreneur. Australian Economic History Review, v. 45, n. 3, p. 244-272, Nov. 2005.

IBGE. Instituto Brasileiro de Geografia e Estatística. As fundações privadas e associações sem fins lucrativos no Brasil. 7 ago. 2008. Disponível em: <ftp.ibge.gov.br/Fundacoes_Privadas_e_Associacoes/>. Acesso em: 13 jan. 2009.

JAMES, Kim T.; ARROBA, Tanya. Reading and carrying: a framework for learning about emotion and emotionality in a organizational systems as a core aspect of leadership development. Management Learning, v. 36, n. 3, p. 299-316, Sept. 2005.

JOSÉ JUNIOR. Da favela para o mundo: a história do grupo cultural Afro Reggae. Rio de Janeiro: Ediouro, 2006.

LAVALLE, Adrian G.; CASTELLO, Graziela. Sociedade, representação e a dupla face da accountability: Cidade do México e São Paulo. Cadernos. CRH, v. 21, n. 52, p. 67-86, abr. 2008.

LEZANA, Álvaro G.R.; TONELLI, Alessandra. O comportamento do empreendedor. In: DE MORI, Flavio (Org.). Empreender: identificando, avaliando e planejando um novo negócio. Florianópolis: Escola de Novos Empreendedores, 2004.

LI, Jun. Political strategy of Chinese private ventures: an organizational life cycle framework. International Journal of Entrepreneurship, v. 12, p. 107-124, 2008.

LINDNER, Leandro. Enong - Encontro Nacional de ONG-Aids: construção de sonhos e lutas. Curitiba: Domo, 2005.

LUGO MORIN, Diosey R. Reflexión teórica sobre la validez de los preceptos de acción social de Max Weber para el análisis del campesinado actual. Ambiente \& Sociedade, v. VIII, n. 2, p. 29-36, jul./dez. 2005.

LUKSETICH, William. Government funding and nonprofit organizations. Nonprofit and Voluntary Sector Quarterly, v. 37, n. 3, p. 434-442, Sept. 2008.

MARCONI, Marina A.; LAKATOS, Eva M. Metodologia do trabalho científico. São Paulo: Atlas, 2001. v. 6.

MATIAS, Eduardo F.P. Estado soberano, globalização e o papel da sociedade civil transnacional. Conferência Internacional. Instituto Ethos. 42 slides, color. Microsoft PowerPoint 2006. Disponível em: <www.ethos.org.br/ci2006/materia.asp?id=57>. Acesso em: 14 dez. 2008.

MATTAR, João. Metodologia científica na era da informática. 2. ed. São Paulo: Saraiva, 2005.

MILANI, Carlos R.S. O princípio da participação social na gestão de políticas públicas locais: uma análise de experiências latino-americanas e europeias. Revista de Administração Pública, Rio de Janeiro, v. 42, p. 551-579, 2008. 
MORGAN, Gareth; SMIRCICH, Linda. The case for qualitative research. Academy of Management Review, v. 5, n. 4, p. 491-500, 1980.

MSF. Médicos Sem Fronteiras. s.d. Disponível em: <www.msf.org.br>. Acesso em: maio 2011.

NICHOLLS, Alex. The legitimacy of social entrepreneurship: reflexive isomorphism in a pre-paradigmatic field. Entrepreneurship: Theory and Practice, v. 34, n. 4, p. 611-633, 2010.

NORTHOUSE, Peter G. Leadership: theory and practice. Califórnia: Sage, 2004.

PARAMESHWAR, Sangeeta. Inventing higher purpose through suffering: the transformation of the transformational leader. The Leadership Quarterly, v. 17, p. 454-474, 2006.

PEREIRA, Breno A.D.; PEDROZO, Eugenio A. Contribuições à consolidação da teoria estratégica interorganizacional: uma análise dos relacionamentos horizontais. Revista de Administração Contemporânea, v. 9, n. 4, p. 141-161, out./dez. 2005.

PHELPS, Robert; ADAMS, Richard; BESSANT, John. Life cycles of growing organizations: a review with implications for knowledge and learning. International Journal of Management Reviews, v. 9, n. 1, p. 1-30, 2007.

ROCHA, Ana A.; FELDMANN, Fabio. A Mata Atlântica é aqui. E daí?: história e luta da Fundação SOS Mata Atlântica. São Paulo: Terra Virgem, 2006.

SCHUMPETER, Joseph A. Teoria do desenvolvimento econômico: uma investigação sobre lucros, capital, crédito, juro e o ciclo econômico. São Paulo: Abril Cultural, 1982.

SCOTT, Mel; BRUCE, Richard. Five stages of growth in small business. Long Range Planning, v. 20, n. 33, p. 45-52, June 1987.

SEN, Amartya. Desenvolvimento como liberdade. São Paulo: Companhia das Letras, 2000.

SEVERINO, Antônio J. Metodologia do trabalho científico. 21. ed. rev. e ampl. São Paulo: Cortez, 2000.

SHARKEN SIMON, Judith; DONAVAN, Terence. The five stages of nonprofit organizations: where you are, where you're going, and what to expect when you get there. Saint Paul: Amherst H. Wilder Foundation, 2004.

SHAW, Eleanor; CARTER, Sara. Social entrepreneurship: theoretical antecedents and empirical analysis of entrepreneurial processes and outcomes. Journal of Small Business and Enterprise Development, v. 14, n. 3, p. 418-434, 2007.

SILVA, Carlos E.G. Gestão, legislação e fontes de recursos no terceiro setor brasileiro: uma perspectiva histórica. Revista de Administração Pública, Rio de Janeiro, v. 44, p. 1301-1325, 2010.

SØRENSEN, Suna; LASSEN, Astrid H.; HINSON, Robert. Towards a conceptualization of entrepreneurship. Journal of Research in Marketing and Entrepreneurship, v. 9, n. 1, p. 89-101, 2007. 
STEVENS, Susan K. Nonprofit lifecycles: stage-based wisdom for nonprofit capacity. Long Lake: Stagewise Enterprises, 2002.

TYSZLER, Marcelo. Mudança social: uma arte? Empreendimentos sociais que utilizam a arte como forma de mudança. Revista de Administração Pública, v. 41, p. 1017-1034, 2007.

VOLTOLINI, Ricardo. Terceiro setor: planejamento e gestão. São Paulo: Senac, 2004.

ZAHRA, Shaker A. et al. A typology of social entrepreneurs: motives, search processes and ethical challenges. Journal of Business Venturing, v. 24, n. 5, p. 519-532, Sept. 2009.

Alexandre Meira de Vasconcelos é doutorando em engenharia de produção no Programa de Pós-graduação em Engenharia de Produção da Universidade Federal de Santa Catarina (UFSC). E-mail: meira1970@ gmail.com.

Álvaro Guillermo Rojas Lezana é professor associado 3 e diretor acadêmico do Centro de Engenharia da Mobilidade da Universidade Federal de Santa Catarina (UFSC). E-mail: lezana@deps.ufsc.br. 